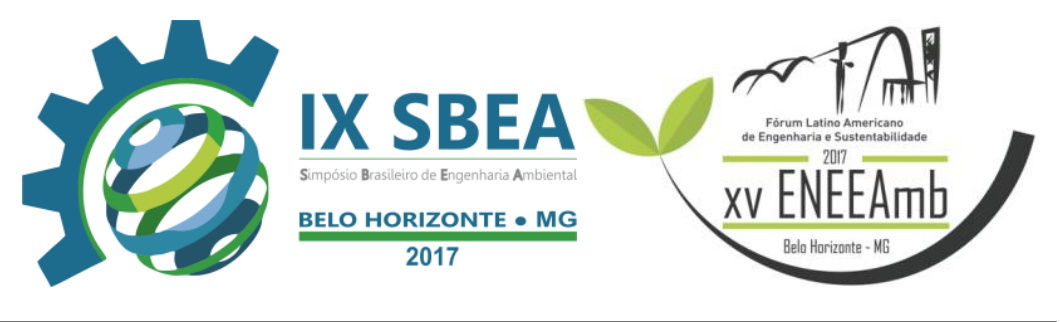

\title{
PERFIL DIAGNÓSTICO QUALITATIVO DO SISTEMA DE DRENAGEM DO BAIRRO DE CANUDOS, BELÉM-PA.
}

Maycol Wanderson Menezes Souza - maycolwms@gmail.com Universidade Federal do Pará (UFPA), Campus Belém.

Franklen dos Santos Cordovil - frank.saint.cord@ gmail.com Faculdade Maurício de Nassau, Campus Belém.

Jonathan Rian Farias do Vale - jonathan_rian@ hotmail.com Universidade Federal do Pará (UFPA), Campus Belém.

Karla Karoline Leite do Rosário - karlaleite93@ gmail.com

Universidade do Estado do Pará (UEPA), Campus Belém

Mateus Souza Morais - mateussmorais8@gmail.com

Universidade Federal do Pará (UFPA), Campus Belém 


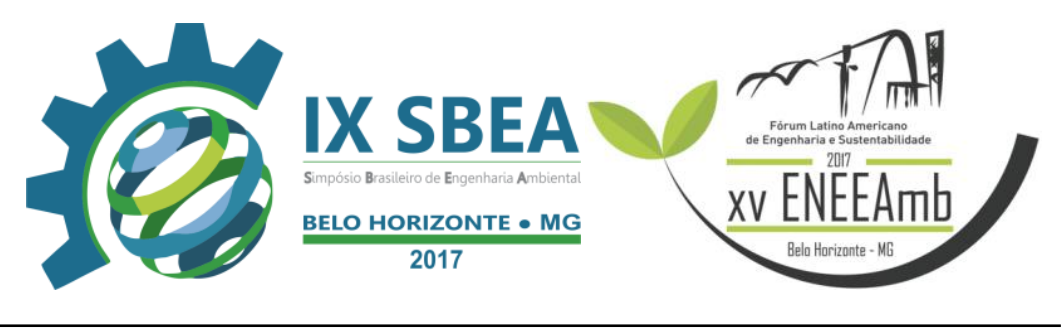

\section{RESUMO}

O processo de urbanização das cidades, além de benefícios, proporciona diversos problemas de ordem econômica, social e ambiental, em decorrência da não consideração do planejamento urbano, ferramenta fundamental na prevenção e controle de Inundações Urbanas, por exemplo, frequentes em cidades onde os serviços de limpeza e manutenção urbana são ineficazes e também onde as águas residuárias combinam-se com as águas provenientes de chuvas intensas, como é o caso da cidade de Belém do Pará. A gestão pública inadequada aliada à falta de sensibilização da sociedade com as questões ambientais configura-se como desafios a serem superados para o equacionamento ou minimização de problemas associados ao saneamento básico ineficiente. Nessa perspectiva, realizou-se o diagnóstico das estruturas do Sistema de Drenagem Urbana, em área pertencente à sub-bacia hidrográfica do Rio Tucunduba, e a proposição de medidas de melhorias e considerações sobre tais estruturas, afim de que esse ensaio prévio possa servir como um facilitador para o processo de tomada de decisão no que diz respeito à gestão urbana na cidade de Belém.

Palavras-chave: Drenagem, Bacia Rio Tucunduba, Urbanização, Inundações.

\section{INTRODUÇÃO/OBJETIVO}

Os sistemas de físicos de drenagem são constituídos por subsistemas de micro e macro drenagem. A microdrenagem constitui-se de galerias, valetas, revestidas ou valas naturais, poços de visita e bocas de lobo, por onde escoam as águas pluviais com destino aos cursos d'água, enquanto o subsistema de macrodrenagem é constituído por cursos d'água naturais ou canalizados, barragens e comportas para controle de inundações (BELÉM, 2008).

Segundo a Política Nacional de Saneamento Básico, a prestação dos serviços de drenagem urbana constitui um dos princípios fundamentais dentre os serviços públicos de saneamento básico, sendo estes serviços definidos como o conjunto de atividades de:

Drenagem e manejo das águas pluviais, limpeza e fiscalização preventiva das respectivas redes urbanas: conjunto de atividades, infraestruturas e instalações operacionais de drenagem urbana de águas pluviais, de transporte, detenção ou retenção para o amortecimento de vazões de cheias, tratamento e 


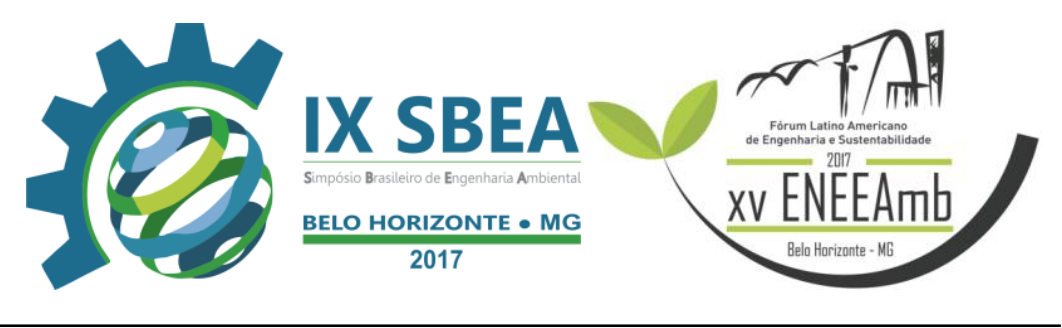

disposição final das águas pluviais drenadas nas áreas urbanas. (BRASIL, 2007, grifo nosso)

O trecho destacado foi integrado recentemente à lei do saneamento de $2007, \mathrm{n}^{\circ}$ 11.445, por meio da lei $n^{o} 13.308$ de 6 de Julho de 2016, esta alteração destaca a necessidade de se haver não só a implantação dos sistemas de drenagem, mas também a sua constante manutenção, visando atender de maneira contínua a eficiência objetivada em seu projeto. O potencial máximo de um sistema de drenagem é comprometido sempre nos casos em que se ocorre a obstrução das vias por onde as águas pluviais irão percorrer, isto ocorre especialmente no subsistema de microdrenagem devido à sua menor dimensão.

Deste modo, pretende-se identificar o atual estado de uma das estruturas responsáveis pelo sistema de drenagem urbana do bairro de Canudos, em Belém do Pará, limitando os estudos ao canal da Av. Gentil Bittencourt para avaliar as atuais condições em seu interior e nas demais estruturas adjacentes que contribuem em sua vazão final.

Pretende-se também fazer um levantamento bibliográfico em bancos de dados da prefeitura ou demais fontes da literatura científica local, explanando as configurações hidrográficas às quais o curso d'água está inserido. E será também realizado um levantamento fotográfico dos principais problemas encontrados no local.

\section{METODOLOGIA}

Para a elaboração desta pesquisa, realizou-se levantamento bibliográfico acerca do tema "Drenagem Urbana" e busca de dados referentes à cidade de Belém e do bairro de Canudos nos órgãos competentes, tais como a Secretaria Municipal de Saneamento, (SESAN), e no Instituto Brasileiro de Geografia e Estatística (IBGE). Bem como, foram realizadas visitas in loco no bairro para delimitação e identificação de problemas relacionados à drenagem urbana. As visitas foram feitas no mês de março de 2017, imediatamente após chuvas intensas, para que se pudesse melhor visualizar seus efeitos no bairro. Depois de realizadas as visitas técnicas, confeccionou-se um relatório técnico com as principais observações. Com as anotações organizadas, os principais problemas 


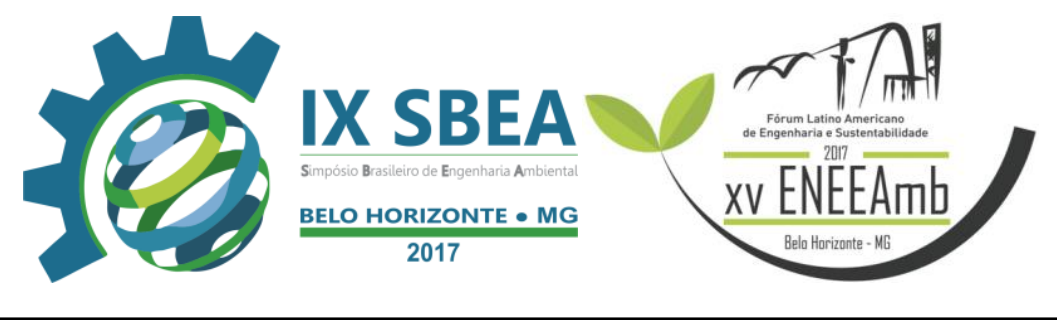

encontrados no sistema de drenagem foram listados. Ao final, foram propostas algumas recomendações de resoluções para a problemática verificada.

\section{1- DESCRIÇÃO DA ÁREA DE ESTUDO}

A área de estudo corresponde ao Bairro de Canudos na cidade de Belém do Pará pertencente a sub- bacia hidrográfica do Tucunduba, região localizada a sudeste da cidade e de acordo com Silva (2003), possui $10,55 \mathrm{~km}^{2}$ de área e é considerada a segunda maior bacia hidrográfica de Belém, e atinge além do Bairro de Canudos os bairros universitários, Terra Firme, Guamá, e Marco, totalizando uma população de aproximadamente 161.499 habitantes.

Ainda segundo Silva (2003) a sub-bacia em questão é composta por 13 canais, no entanto, o canal visitado para a realização deste trabalho foi o da Avenida Gentil Bittencourt e será descrito na seção Resultados e Discussão

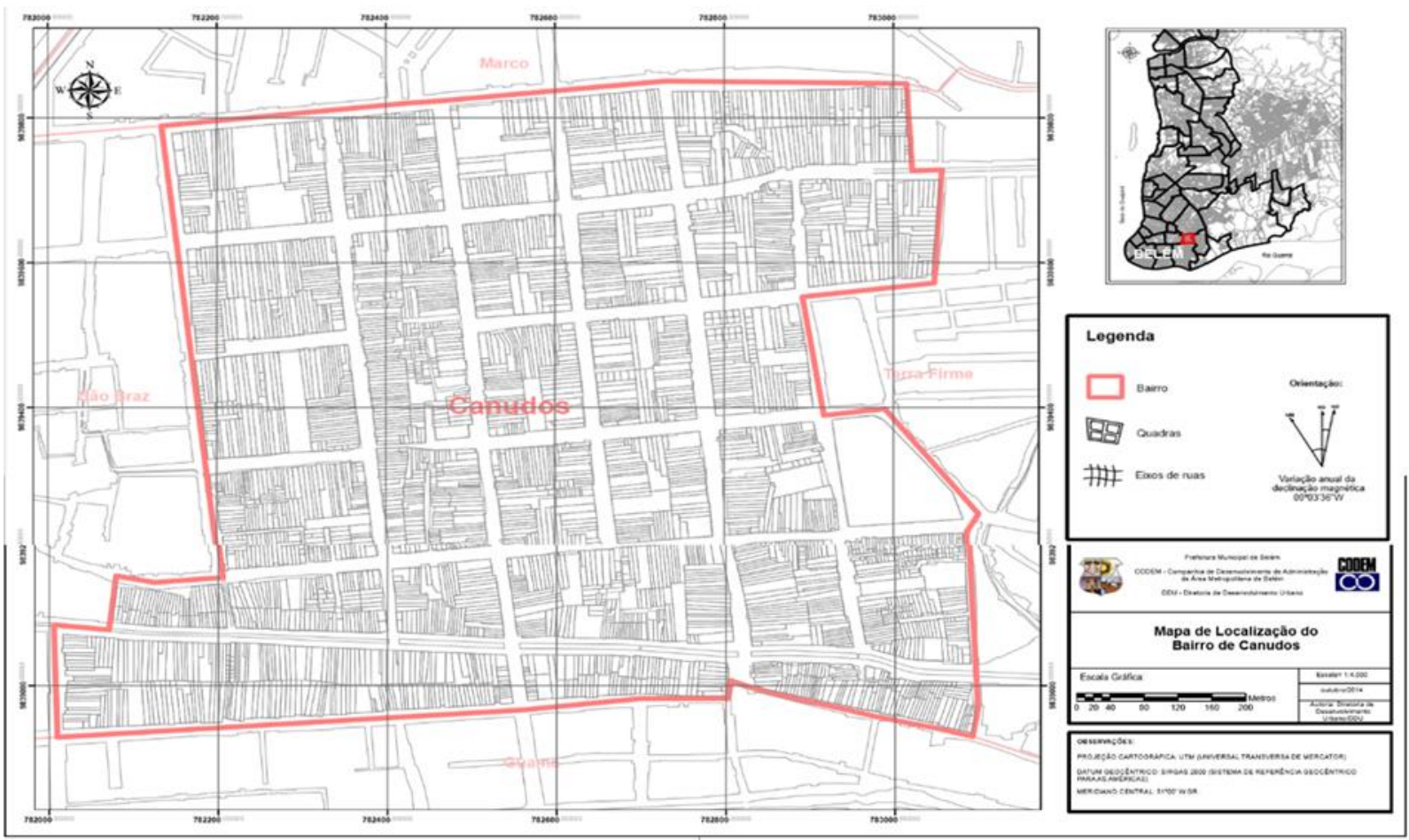

Figura 1: Mapa de localização da área de estudo

Fonte: Adaptada do plano diretor do município de Belém 


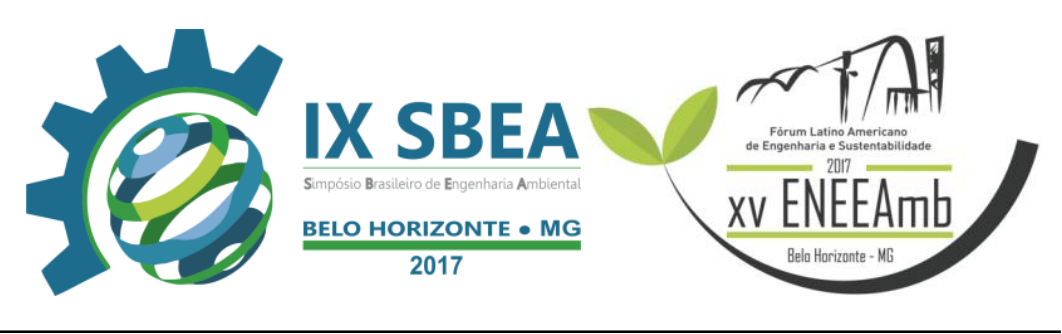

\section{RESULTADOS E DISCUSSÃO}

\subsection{DIAGNÓSTICO DAS SARJETAS}

As sarjetas são dimensionadas com o propósito de escoar a água da chuva e minimizar a ocorrência de inundações urbanas e consequentemente proporcionarem qualidade de vida, porém é necessário analisar as condições de saneamento do local. Com o objetivo de diagnosticar as condições sanitárias da Avenida Teófilo Conduru, realizou- se visita, e observou-se o comprometimento do fluxo do escoamento da água, em razão, do acúmulo de resíduos sólidos urbanos e também o despejo de esgoto doméstico diretamente sob as sarjetas.

De acordo com moradores do bairro, o local é atendido por serviço de coleta de resíduos sólidos urbanos da Prefeitura, duas vezes por semana, mesmo assim percebe-se o acúmulo de grande quantidade de resíduos nas esquinas e nas proximidades das residências em dias não atendidos pela coleta. Além disso, observou-se o inadequado acondicionamento do material. Verificou-se no dia da visita a presença de animais revolvendo os sacos plásticos, onde estavam armazenados os resíduos sólidos, e com a chegada da chuva o material foi carreado e depositado nas sarjetas.

Além de resíduos sólidos, o sistema de drenagem recebe lançamento de esgoto doméstico in natura, extrapolando a capacidade de escoamento das sarjetas, isso favorece o alagamento, como foi verificado em alguns trechos da Avenida Teófilo Conduru, gerando inconvenientes para a circulação de pedestres, ciclistas e motoristas que precisam passar pelo local.

\subsection{DIAGNÓSTICO DAS BOCAS DE LOBO}

O principal problema detectado nas bocas de lobo também foi o acúmulo de resíduos sólidos e a chegada de esgoto sanitário. Esse acúmulo de material indesejado no sistema reduz a capacidade das bocas de lobo de receberem as vazões para as quais foram dimensionadas. Além disso, a disposição de bocas de lobo em locais inadequados também foi verificada, causando transtornos para a população (CANHOLI, 2005).

\subsection{DIAGNÓSTICO DO CANAL DA AVENIDA GENTIL BITTENCOURT}

O canal da Avenida Gentil Bittencourt representa uma obra de macrodrenagem de geometria de seção transversal do tipo retangular. Através de visita ao local observou-se a ocorrência de vários problemas. O canal encontra-se tomado por grande 


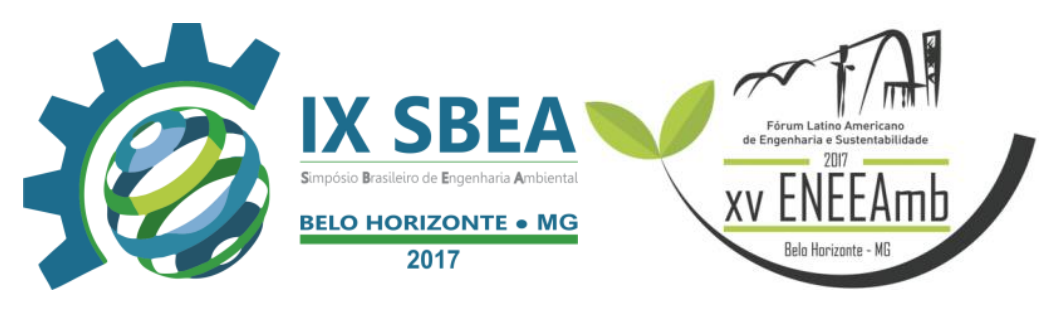

quantidade de resíduos sólidos, decorrentes do processo de ocupação sem planejamento ao longo de suas margens, da falta de conscientização da população e, sobretudo, do abandono por parte do poder público em relação ao saneamento básico da área, mostrando que a coleta na área é ineficiente (TUCCI,1997).

No entorno do canal, observou-se o processo erosivo do solo devido às chuvas, favorecendo o acúmulo de sedimentos dentro do curso d'água e seu assoreamento, transbordamento e ainda o alagamento da via. Juntamente com os resíduos sólidos lançados de forma inadequada identificou-se o lançamento de esgotos sem tratamento prévio no canal, o que poderá favorecer a ocorrência de doenças de veiculação hídrica.

Quanto ao revestimento dos taludes, observou-se que o Canal da Avenida Gentil Bittencourt, é revestido com concreto. E em relação às muretas de proteção do canal, percebeu-se que estavam quebradas, comprometendo a integridade física das pessoas.

\section{CONCLUSÕES/RECOMENDAÇÕES}

Ao longo da pesquisa observou-se que o Canal de Macrodrenagem da Avenida Gentil Bittencourt, está praticamente abandonado, em razão da falta de compromisso da população residente no entorno, assim como do déficit nos serviços de limpeza e manutenção dos canais e das vias públicas prestados pela Prefeitura Municipal de Belém.

Diante desse quadro, percebe-se a necessidade da conscientização e sensibilização da população no sentido de não possibilitar a chegada de resíduos sólidos e esgoto ao sistema de drenagem de água pluvial, assim como a adoção de serviços públicos de limpeza e coleta de resíduos sólidos pela Secretária de Saneamento de Belém (SESAN), e obras de esgotamento sanitário.

Quando se projeta um canal leva-se em consideração a premissa de utilização do escoamento apenas da água precipitada, no entanto, verificou- se através da visitação o acúmulo de grande quantidade de resíduos sólidos dos mais variados tipos e o despejo de esgoto sanitário em diversos trechos do Canal da Gentil. Esses problemas combinados com as chuvas intensas de Belém do Pará possibilitam a ocorrência de inúmeros prejuízos, frequentes na área analisada, principalmente decorrentes das inundações urbanas (SILVA, 2003). 


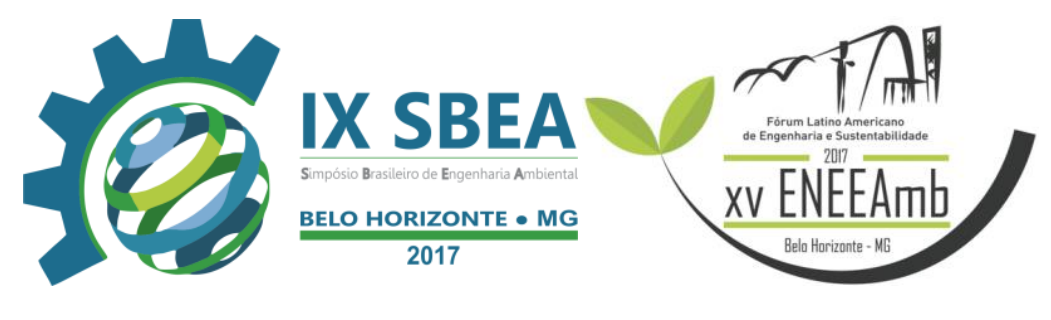

Sugere-se para o equacionamento ou minimização dos impactos ocasionados pelo uso inadequado do canal, a sensibilização ambiental da população mais afetada a fim de que possam conviver em um ambiente salutar para que atuem como "fiscalizadores" em prol dos benefícios advindos dessa preservação ambiental. Também é importante o cumprimento adequado das atividades de limpeza e manutenção do sistema via- canal pela Secretaria Municipal de Saneamento (SESAN), de Belém, através da realização de coletas de resíduos sólidos com maior frequência e ainda a dragagem dos canais.

Os principais problemas detectados no sistema de Microdrenagem, o qual, deveria apenas escoar a água da chuva, foram o acúmulo de resíduos sólidos diversos, e a instalação de bocas de lobo em locais inadequados, prejudicando o escoamento e acarretando inconvenientes como o alagamento de vias e a exposição da população a contaminação por via hídrica devido ao despejo de esgotos nas sarjetas. Essas contribuições adicionais chegam até o Canal e ocasionam mais inconvenientes.

Belém ainda é carente quando o assunto é drenagem urbana, principalmente devido seu processo de urbanização ter ocorrido de forma caótica, em especial nas regiões periféricas. Somado a isso, a população necessita de informações que possibilitem a relação harmoniosa com o meio ambiente, e maior responsabilidade do poder público com a limpeza dos canais e logradouros.

Dessa forma, os serviços de drenagem urbana são essenciais no controle e prevenção de Inundações, e devem ser analisados em conjunto com o manejo e limpeza pública de resíduos sólidos urbanos e também com a infraestrutura de esgotamento sanitário, a fim de possibilitar a qualidade de vida da população.

\section{REFERÊNCIAS BIBLIOGRÁFICAS}

BELÉM. Lei no 8.655, de 30 de julho de 2008. Plano Diretor do Município de Belém. DOU, 2008.

BRAGA, B. D. F. Gerenciamento urbano integrado em ambiente tropical. In: Seminário de hidráulica computacional aplicada a problemas de drenagem urbana, 1994, São Paulo. Anais. São Paulo: ABRH, 1994. 


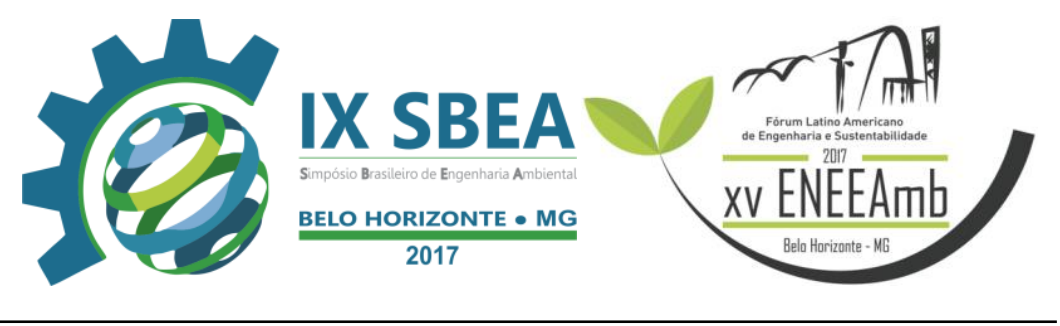

CANHOLI, A. P. Drenagem Urbana e Controle de Enchentes, Oficina de Textos, São Paulo, 2005.

IBGE. Tendências demográficas: uma análise da população com base nos resultados dos Censos Demográficos de 1940 e 2000. Disponível em: <http://www .ibge.gov.br/home/>. Acesso em: 22 jan. 2017.

PREFEITURA MUNICIPAL DE BELÉM - Secretaria Municipal de Saneamento SESAN. Disponível em: <www.belem.pa.gov.br>. Acesso em: 22 jan. 2017.

TUCCI, C. E. M. Plano diretor de drenagem urbana: princípios e concepção. Revista Brasileira de Recursos Hídricos, v. 2, n. 2, p. 5-12, jul. /dez. 1997.

SILVA, A. M. Gestão de conflitos pelo uso da água em bacias hidrográficas urbanas. Dissertação de mestrado. UFPA - BELEM- P. 2003. 